\title{
Analysis of e-commerce transaction system's division of labor based on essential services quantity
}

\author{
Li Wang, Yueting Chai and Yi Liu \\ National Engineering Laboratory for E-Commerce Technologies, \\ Tsinghua University, Beijing, China
}

Analysis of e-commerce

\begin{abstract}
Purpose - The division of labor of e-commerce transaction system is an important research topic. However, there is a certain disparity between the current mainstream research model and the reality, which leads to a biased result. This paper aims to find the effects of transaction efficiency on the evolution of e-commerce transaction system's division of labor and the relationships between the results and other parameters.
\end{abstract}

Design/methodology/approach - This paper puts forward a definition of transaction efficiency based on transaction services and establishes a model of middleman's specialized production decision of transaction services on this basis.

Findings - The research results show that the transaction efficiency plays an important role on the change of middlemen's division of labor level. The degree of economic specialization, price of commodities and transaction services and other associated factors also affect middlemen's division of labor.

Originality/value - This paper is of great significance for evaluating the development level and forecast the development direction of e-commerce.

Keywords Simulation, E-commerce, Optimization model, Division of labor, Transaction efficiency

Paper type Research paper

\section{Introduction}

In recent years, with the deepening application of information technology, e-commerce became a more important role in the world economic system and gradually became the new economic growth of many countries. At present, there are many different kinds of models of e-commerce, and the corresponding transaction system structures are also varied. In addition to the producers and consumers, the third-party transaction platforms, logistics service providers, payment middlemen are also important in these e-commerce models. They provide commodity circulation services to realize the trade of commodities, and we call them middlemen. Different kinds of middlemen constitute the e-commerce transaction systems (Figure 1).

(C) Li Wang, Yueting Chai and Yi Liu. Published in the International Journal of Crowd Science. Published by Emerald Publishing Limited. This article is published under the Creative Commons Attribution (CC BY 4.0) licence. Anyone may reproduce, distribute, translate and create derivative works of this article (for both commercial and non-commercial purposes), subject to full attribution to the original publication and authors. The full terms of this licence may be seen at http:// creativecommons.org/licences/by/4.0/legalcode
Received 15 August 2017 Accepted 28 August 2017 
IJCS

1,3

198

Middlemen could be divided into two types. The first type of middlemen does not have the ownership of commodities. They provide transaction services and earn a profit by selling the services to others, such as e-commerce platforms providing information services, logistics companies providing logistics services, banks and other payment companies providing payment services and so on. The second type of middlemen have the ownership of commodities and earn a profit by selling the commodities to others. They organize the transaction themselves and use the information services, logistics services and payment services provided by the first type of middlemen to finish the transaction. Chandler (1978) called the former commission middlemen and the latter markup middlemen.

This makes us curious about the evolution of the division of labor in e-commerce transaction system. How many types of middlemen would exist in the future? What services would they provide? We study the decisions of middlemen about the division of labor in ecommerce transaction system to solve these problems in this paper.

The study on the division of labor started in eighteenth century. Smith (2015) put forward the origin of the division of labor in an Inquiry into the Nature and Causes of the Wealth of Nations. He believed that different producers have different production efficiencies to produce different products, which forms the absolute advantages of producers. Producers would produce the products in which they have an absolute advantage, thus the division of labor appears. Ricardo (1913) proposed the theory of comparative advantage. He thought absolute advantage is not the necessary condition for trade. Producers could just produce the commodities with more advantages than other commodities to benefit from the division of labor and trade. Heckscher and Ohlin came up with Heckscher-Ohlin Theorem (Krugman, 2008). They thought the differences between the abundance and the price of production factors in different countries lead to different prices of commodities before trade, resulting in the generation of division of labor and trade between different countries. Yang (2003) deemed that the level of the division of labor is determined by the conflict between incomes and transaction costs brought by the division of labor. As long as the increased benefits outweigh the transaction costs, the level of division of labor will improve.

In this paper, transaction efficiency is regarded as the dynamic of the evolution of specialized production in e-commerce transaction system.

\section{Transaction efficiency}

\subsection{An overview of transaction costs and transaction efficiency}

Transaction efficiency is evolved from transaction costs. The idea of transaction costs was first come up with by Coase (1937). He thought transaction costs include the cost of

Figure 1.

The structure of transaction systems

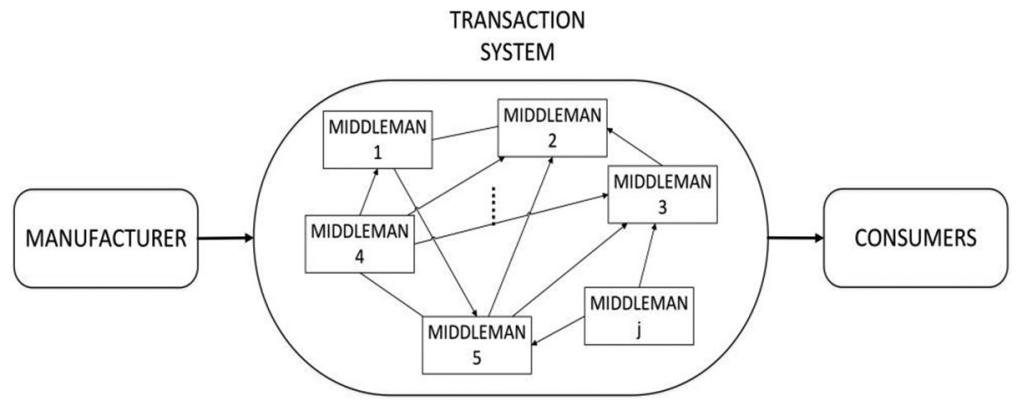


discovering what the relevant prices are and the costs of negotiating and concluding a separate contract for each exchange transaction which takes place on a market. Williamson (1977) developed transaction costs theory based on Coase's work. He proposed three key concepts in transaction cost theory: assets specificity in the technical issues, bounded rationality hypothesis about the human nature and opportunism on the behavior aspect to explain what causes transaction costs. Up till now, researchers' views about transaction costs are not unified. Different researchers came up with different definitions of transaction costs from different perspectives. The transaction cost is a comprehensive concept, which makes it difficult to quantify when analyzing economic problems. In this background, the economists represented by Yang (2003) put forward the concept of transaction efficiency.

Yang used Samuelson's Iceberg Transport Cost model to definite transaction efficiency. When a buyer purchases 1 unit of product, he can only get $k$ unit of product, where $1-k$ unit of product melts as ice during transaction process. The $1-k$ unit of product could be called transaction costs, which include the costs of transportation, implementation of transaction, storage, payment and so on. Thus, $k$ could be considered as the transaction efficiency. Sheng (1992) defined transaction efficiency - the ratio of transaction gains and transaction expenses. Ma (2014) believed transaction efficiency refers to the volume or number of transactions implemented when inputting certain transaction essential factors in the constraints of existing system and other technical conditions. Gao (2007) thought transaction efficiency is the contrast between the revenue of division of labor and transaction costs.

\subsection{Transaction efficiency based on essential services quantity}

The above definitions of transaction efficiency are all associated with prices and costs of commodities. Although the transaction efficiency is related to the characters of commodities, making such an idea could express the level of transaction to some extent, and there are still some problems. The prices of commodities are influenced by supply and demand in the market. For one kind of commodities, the price changes in different periods, and the transaction efficiency should change at the same time. However, the transaction efficiency of one kind of commodities does not change, which leads to a contradiction. Therefore, transaction efficiency should be measured by the quantity of transaction services instead of the price of transaction services.

To define transaction efficiency, we put forward to a concept, which is essential services quantity.

Definition 2.1. Essential services quantity is the quantity of services need to use when completing a transaction.

Essential services quantity is a real number no less than 1 .

Based on the definition of essential services quantity, we define transaction efficiency as follows.

Definition 2.2. Transaction efficiency is the reciprocal of essential services quantity.

Let $s$ be essential services quantity and $\mathrm{k}$ be transaction efficiency, then we have:

$$
k=\frac{1}{s}
$$

Because $s \geq 1$, we have $0<k \leq 1$, i.e.:

$$
k \in[0,1]
$$




\section{IJCS \\ 1,3}

\section{Model building}

\subsection{Problem description}

In this paper, we study the decision problem about the production and trade of transaction services of a middleman with constant resources. Assume there is one kind of commodity trade in the market. The supply of commodity is unlimited. To complete a transaction, there are four kinds of transaction services needed: organizing transaction services, information services, logistics services and payment services. The quantities demanded of the services above are the same in a transaction, i.e. the ratio is 1:1:1:1.

A middleman chooses one to four kinds of transaction services to provide. If a middleman wants to sell the commodities as a distribution middleman, he has to produce organizing transaction services which are not allowed to trade. The quantity of the commodities sold by a middleman depends only on the quantity of organizing transaction services produced by the middleman. However, information services, logistics services and payment services are allowed to trade. When a middleman sells commodities, he should ensure the quantity of information services, logistics services and payment services are no less than one of the organizing transaction services. Thus, if any kind of the three kinds of services above produced by the middleman are less than the organization transaction services, he has to buy the corresponding kind of services to meet the requirements. On the contrary, if any of the three kinds of services above produced by the middleman is more than the organization transaction services, he could sell the surpluses.

\subsection{Model}

Let $w, x, y$ and $z$ be the production of organizing transaction services, information services, logistics services and payment services, respectively. The production functions of transaction services are as follows:

$$
w=l_{w}^{a} x=l_{x}^{b} \quad y=l_{y}^{c} z=l_{z}^{d}
$$

where $a, b, c$ and $d$ are the degree of specialization economy of organizing transaction services, information services, logistics services and payment services, respectively. We believe that there are increasing returns to scale in the production of transaction services. Thus, we have:

$$
a>1 b>1 c>1 d>1
$$

Let $l_{i} \in[0,1](i=w, x, y, z)$ be the resource used to produce the service $i$. We think the total resource of a middleman is constant, and we let it be 10 , so we have:

$$
l_{w}+l_{x}+l_{y}+l_{z} \leq 10
$$

Let $N$ be the quantity of commodity sold by a middleman, then:

$$
N=\frac{w}{s}=w k
$$

where $s$ is essential services quantity, and $k$ is transaction efficiency.

If $i>w(i=x, y, z)$, the middleman has $i-w$ units of transaction services to sell. If $i<$ $w(i=x, y, z)$, the middleman has to buy $w-i$ units of transaction services. The profit function is: 


$$
P=p_{g} N+p_{x}(x-w)+p_{y}(y-w)+p_{z}(z-w)
$$

Analysis of e-commerce

where $p_{c}, p_{x}, p_{y}$ and $p_{z}$ are the prices of commodity, information services, logistics services and payment services, respectively.

The optimal specialized production mode decision problems of a middleman are as follows:

$$
\begin{gathered}
\max P=p_{g} N+p_{x}(x-w)+p_{y}(y-w)+p_{z}(z-w) \\
\text { s.t. }\left\{\begin{array}{l}
x=l_{x}^{a}, \quad y=l_{y}^{b} \\
z=l_{z}^{c}, \quad w=l_{w}^{d} \\
l_{x}+l_{y}+l_{z}+l_{w} \leq 10 \\
N=w k \\
0 \leq k \leq 1
\end{array}\right.
\end{gathered}
$$

To simplify the model, we think that the degree of specialization economy of information service, payment service and logistics service economy are the same, i.e.:

$$
a=b=c=d
$$

Thus, the decision problem could be rewritten as follows:

$$
\begin{aligned}
& \max P=p_{g} N+ p_{x}(x-w)+p_{y}(y-w)+p_{z}(z-w) \\
& \text { s.t. } \quad\left\{\begin{array}{l}
x=l_{x}^{a}, \quad y=l_{y}^{a} \\
z=l_{z}^{a}, \quad w=l_{w}^{a} \\
l_{x}+l_{y}+l_{z}+l_{w} \leq 10 \\
N=w k \\
0 \leq k \leq 1
\end{array}\right.
\end{aligned}
$$

\section{Simulation and analysis}

We consider a transaction system with 100 middlemen. Every middleman has to decide how much resource should be distributed to four kinds of services. The prices of commodities, information services, logistics services and payment services are determined by the relationships between supplies and demands of the services in the system. The higher the supply is, the lower the price is. The higher the demand is, the higher the price is. The price functions of commodity are as follows:

$$
p_{g}=g_{g}-h_{g} N_{t}
$$

The price functions of transaction services are as follows:

$$
p_{i}=g_{i}-h_{i}\left(i_{t s}-i_{t d}\right), i=x, y, z
$$

where $N_{t}$ is the total quantity of commodities sold in the system, $i_{t s}(i=x, y, z)$ is the total supply of service $i$ in the system and $i_{t d}(i=x, y, z)$ is the total demand of service $i$ in the system. 
IJCS

1,3

To simplify the model, we think that the price functions of information services, logistics services and payment services are the same. The gradients of transaction services price functions and commodity price function are the same, i.e.:

$$
g_{x}=g_{y}=g_{z}
$$

$$
h_{x}=h_{y}=h_{z}=h_{w}
$$

The rules of simulation:

If the total supply $i_{t s}(i=x, y, z)$ of service $i$ is less than the total demand $i_{t d}(i=x, y, z)$, then every demander can get $i_{t s} i_{m d} / i_{t d}$, where $i_{m d}(i=x, y, z)$ is the demand of the middleman.

If the total supply $i_{t s}(i=x, y, z)$ of service $i$ is more than the total demand $i_{t d}(i=x, y, z)$, then every supplier can sell $\left.i_{t d} i_{m s}\right) i_{t}$, where $i_{m s}(i=x, y, z)$ is the supply of the middleman.

The quantity of commodities sold by a middleman is determined by the minimum service.

When every circulation ends, every middleman decreases a constant quantity of resource used to produce the service with the minimum profit and use the resource to produce the service with the maximum price.

The promotion of transaction efficiency is the dynamic of middlemen's specialized production evolution. And other parameters of the model have different effects on the evolution.

We use the uncorrected sample standard deviation of the resource used to produce four kinds of services to measure the levels of division of labor. A higher sample standard deviation means a higher level of division of labor.

\subsection{The effect of degree of economic specialization}

The degree of economic specialization reflects the middlemen' production level of transaction services. Take the other parameters as follows:

Commodity equilibrium price $e=1000$

Transaction services equilibrium price $g=500$

Price gradient $h=1$

Different degrees of economic specialization's effects on the distribution of middlemen's resource are shown from Figure 2 to Figure 4, and the uncorrected sample standard deviations of the resource are shown in Figure 5.

Through the above results, we can see that with the improvement of transaction efficiency, the level of division of labor first ascends and then descends. Because the improvement of transaction efficiency decreases the costs of buying transaction services, which makes middlemen are able to put more resource to produce the service with highest profit. However, with the further improvement of transaction efficiency, there is no need to buy service from the market for middlemen. The services they produce themselves can satisfy their demand. Thus, the level of division of labor descends.

With the higher degree of economic specialization, the level of the division of labor is lower. With the high degree of economic specialization, middlemen's production capacity is much greater than the demand of the market. Thus, there is no need for middlemen to specialize in the production. 


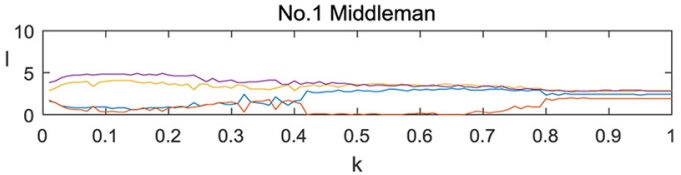

Analysis of e-commerce
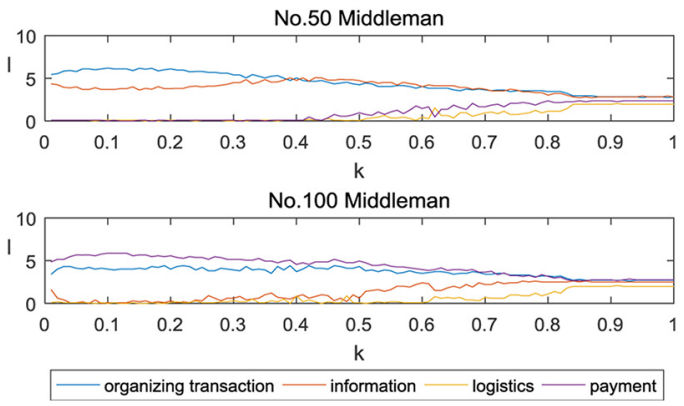

Figure 2.

Degree of economic specialization $\mathrm{a}=3$
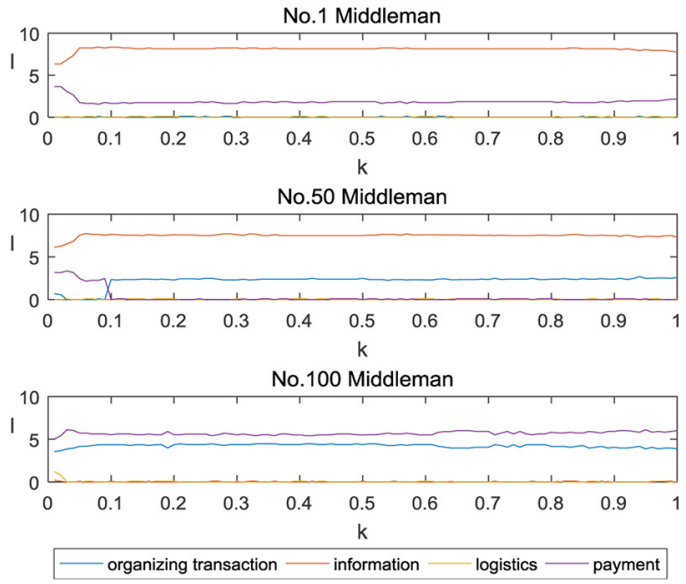

Figure 3. Degree of economic specialization $\mathrm{a}=2$

\subsection{The effect of price gradient}

The price gradient reflects the level of the price affected by the supply and demand. Take the other parameters as follows:

Degree of economic specialization $a=3$

Commodity equilibrium price $e=2000$

Transaction services equilibrium price $g=500$

Different price gradients' effects on the distribution of middlemen's resource are shown from Figures 6 to 8, and the uncorrected sample standard deviations of the resource are shown in Figure 9.

Through the above results, we can see that with the improvement of transaction efficiency, the level of division of labor first ascends, then descends and finally ascends again. Because the improvement of transaction efficiency decreases the costs of buying transaction services, which makes middlemen are able to put more resource to produce 
IJCS

1,3

\section{4}

Figure 4.

Degree of economic specialization $\mathrm{a}=1.5$
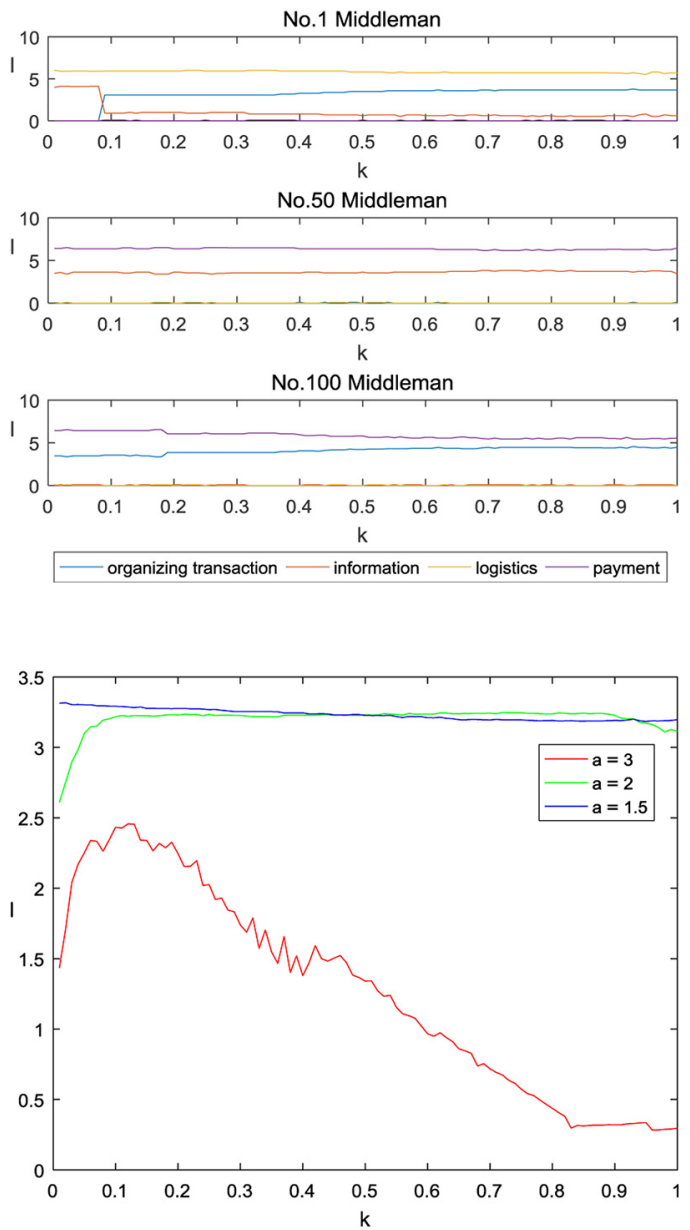

Figure 5.

Uncorrected sample standard deviations the service with highest profit. However, with the further improvement of transaction efficiency, there is no need to buy service from the market for middlemen. The services they produced themselves can satisfy their demands. Thus, the level of division of labor descends. When transaction efficiency reaches a higher value, a higher price gradient makes middlemen to start specialized product again that can help them make more profit.

With low price gradient, middlemen's specialized production level is higher. The service price is not affected much by production. The mass production led by specialization still can make middlemen maintain a higher level of profit. On the contrary, with high price gradient, middlemen's specialized production level reduces. Because the mass production leads to the unit price's fall, the overall profits reduce. At the same time, middlemen's demand of other services increase, leading to the rising of other services' price as well as the costs of middlemen in purchasing other services. 


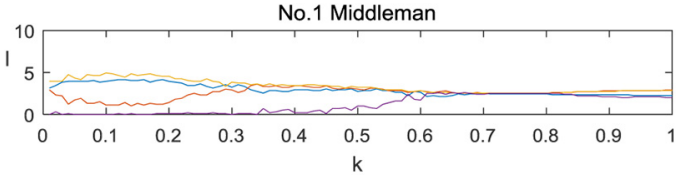

Analysis of e-commerce
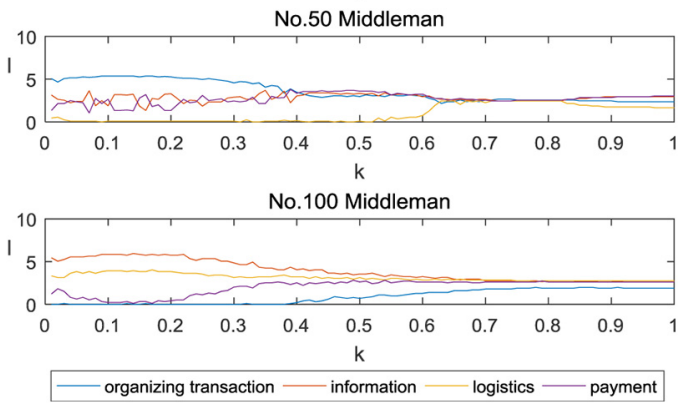

Figure 6. Price gradient $h=1$
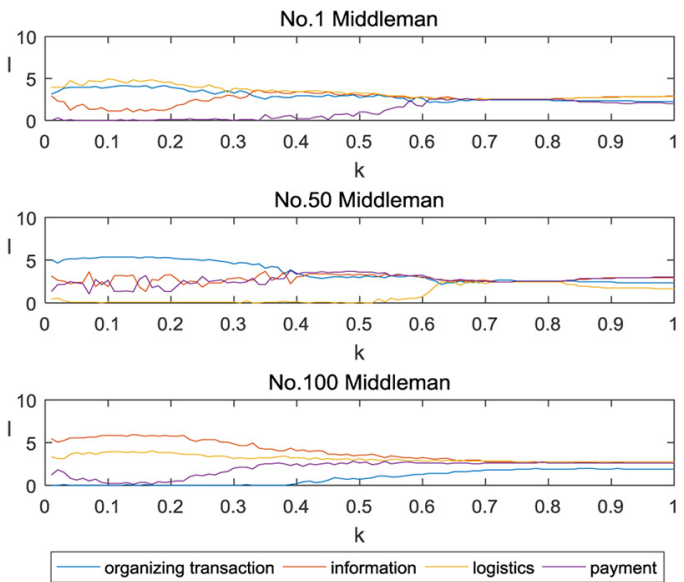

Figure 7.

Price gradient $h=2$

\subsection{The effect of relative equilibrium price}

Relative equilibrium prices refer to the ratio of goods equilibrium price and transaction services equilibrium price $e / g$. Here, we fix services equilibrium price and change commodity price to change the relative equilibrium price. Take the other parameters as follows:

Degree of specialization economy $a=3$

Price gradient $h=2$

Transaction services equilibrium price $g=500$

Different relative equilibrium prices' effects on the distribution of middlemen's resource are shown from Figures 10 to 12, and the uncorrected sample standard deviations of the resource are shown in Figure 13.

Through the above results, we can see that with the improvement of transaction efficiency, the level of division of labor first ascends, then descends and finally ascends 
IJCS

1,3

206

Figure 8.

Price gradient $h=3$

Figure 9.

Uncorrected sample standard deviations
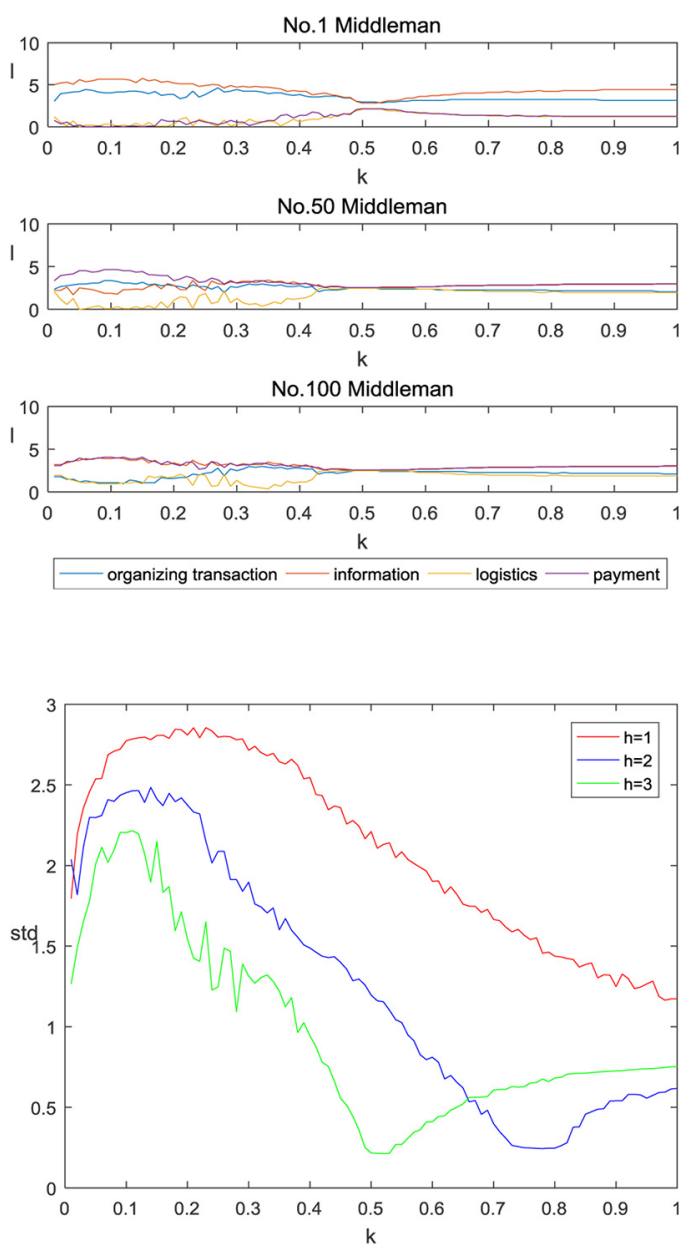

again. The improvement of transaction efficiency decreases the costs of buying transaction services, which makes middlemen able to put more resource to produce the service with highest profit. However, with the further improvement of transaction efficiency, there is no need to buy service from the market for middlemen. The services they produce themselves can satisfy their demand. Thus, the level of division of labor descends. When transaction efficiency reaches a higher value, a lower commodity equilibrium price makes middlemen to start specialized product again for that can help them make more profit.

The higher relative equilibrium price makes the profit of selling commodities greater than that of selling transaction services. There is a re-improvement of division of labor level with lower relative equilibrium price because the transaction services they produce themselves satisfy their need to sell commodities, and they decide to sell more transaction services to make more money. 


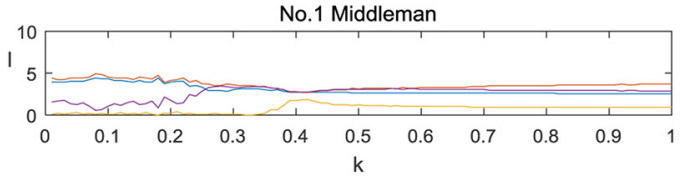

No.50 Middleman
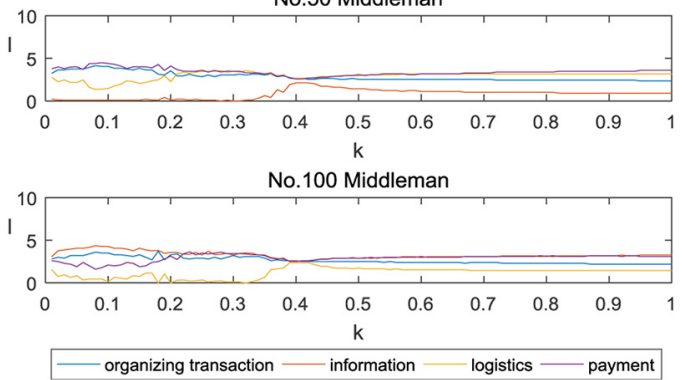

Figure 10.

Commodity equilibrium price $e=1,000$
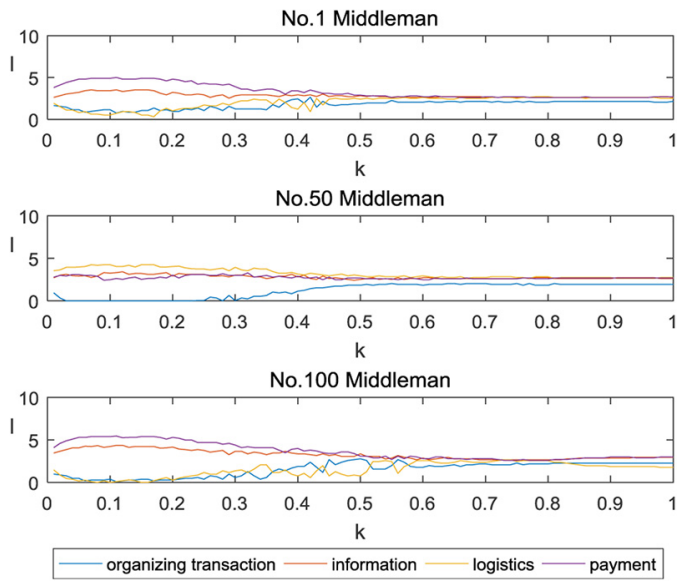

Figure 11. Commodity equilibrium price $e=2,000$

\section{Conclusion}

In this paper, according to the characteristics of the transaction system, we put forward the concept of essential services quantity and come up with a new definition of transaction efficiency. On this basis, we set up a decision model of middlemen's transaction services specialized production. Meanwhile we consider the influence of services' total supply and demand in the market on the prices, which makes the model more real. We simulate the middlemen's decisions to explore the effect of transaction efficiency on middlemen's division of labor and the effect of the degree of specialization economy, the price gradient and the relative equilibrium price on the results.

The results show that with the improvement of transaction efficiency, the level of division of labor first ascends, then descends and may finally ascends again. The improvement of transaction efficiency decreases the costs of buying transaction services, which makes middlemen able to put more resource to produce the service with highest profit. However, with the further improvement of transaction efficiency, there is no need to 
IJCS

1,3

208

Figure 12.

Commodity

equilibrium price

$e=3,000$

\section{Figure 13.}

Uncorrected sample standard deviations
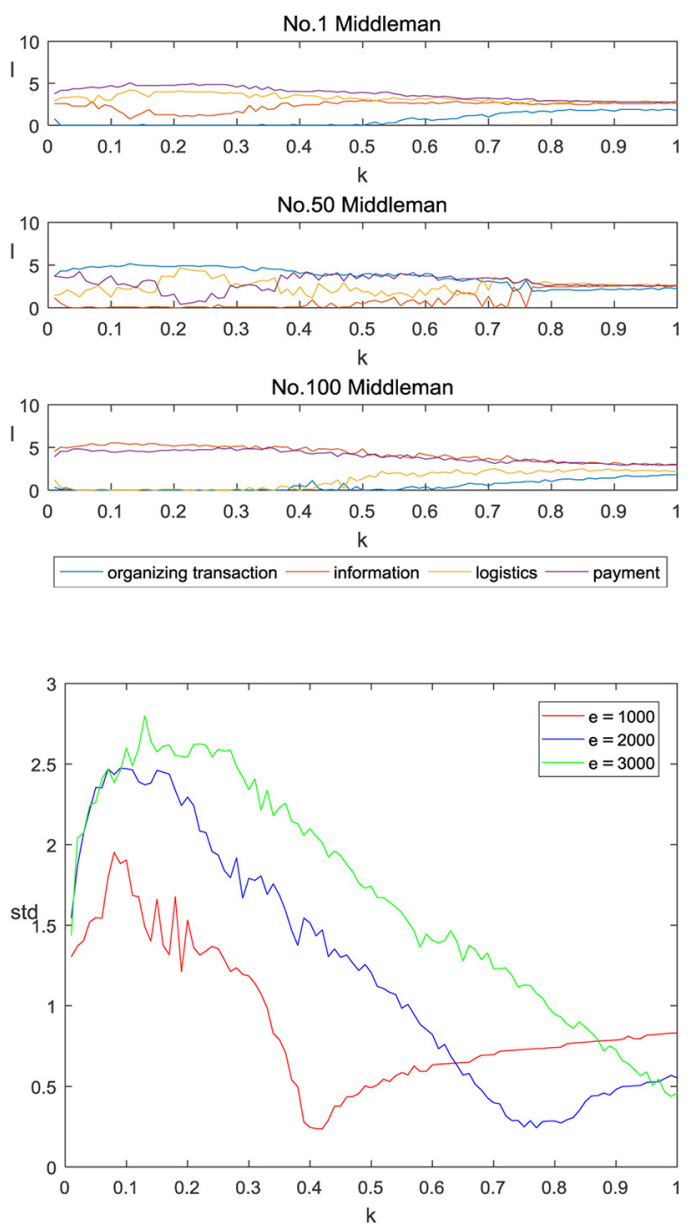

buy service from the market for middlemen. The services they produce themselves can satisfy their demand. Thus, the level of division of labor descends. When transaction efficiency reaches a higher value, a lower commodity equilibrium price or a higher price gradient may make middlemen to start specialized product again for that can help them make more profit.

This research provides a theoretical basis for the evolution of e-commerce transaction system. In the future, the division of labor's level of e-commerce system will fluctuate. Ecommerce middlemen will explore the diversified production models combined with the market situation. The future e-commerce model will be a balance of specialization and diversification.

\section{References}

Chandler, A.D. (1978), "The visible hand”, Business Horizons, Vol. 21 No. 5, pp. 78-81.

Coase, R.H. (1937), "The nature of the firm”, Economica, Vol. 4 No. 16, pp. 386-405. 
Gao, F. (2007), "Transaction efficiency measures and its international comparison: a system of indicators", Finance \& Trade Economics, No. 5, pp. 104-110.

Krugman, P.R. (2008), International Economics: Theory and Policy, Tsinghua University Press, Beijing.

Ma, Q. (2014), Study on the Relationship between China's Trade Efficiency and Economic Growth: A View of Division of Labor, Southwestern University of Finance and Economics.

Ricardo, D. (1913), Principles of Political Economy and Taxation, G. Bell, London.

Sheng, H. (1992), The Division of Labor and the Transactions: A General Theory and its Application to the Problem of Unspecialization in China, SDX Joint Publishing Company, Shanghai.

Smith, A. (2015), An Inquiry into the Nature and Causes of the Wealth of Nations, Tsinghua University Press, Beijing.

Williamson, O.E. (1977), Markets and Hierarchies, Challenge, Vol. 20 No. 1, pp. 70-72.

Yang, X. (2003), Economics: New Classical versus Neoclassical Framework, Social Sciences Academic Press, Beijing.

\section{About the authors}

Li Wang is currently a $\mathrm{PhD}$ candidate of Department of Automation at Tsinghua University, China. He received the bachelor's degree from Tsinghua University in 2013. His research focuses on ecommerce, specialized production, division of labor and complex system.

Yueting Chai is a Professor of Department of Automation at Tsinghua University, China, and the Director of National Engineering Laboratory for E-Commerce Technologies (NELET). He graduated from Department of Automation at Tsinghua University in 1991. His research focuses on e-commerce theory, model, technologies and applications, crowd science and engineering, trust model for ecommerce, etc. Yueting Chai is the corresponding author and can be contacted at: chaiyt@tsinghua. edu.cn

Yi Liu received the MEng degree from Tsinghua University in 1991 and is currently an Associate Professor of Department of Automation, Tsinghua University. Her research interests include supply chain management, modern logistics and e-commerce technology.

For instructions on how to order reprints of this article, please visit our website: 